\title{
An empirical study of comparing DEA and SFA methods to measure hospital units' efficiency
}

\author{
George Katharakis $^{\left({ }^{*}\right)}$, Maria Katharaki ${ }^{\mathrm{b}}$, Theofanis Katostaras ${ }^{c}$ \\ ${ }^{a}$ Ph.D. Candidate National and Kapodistrian University, Athens, Greece \\ ${ }^{\mathrm{b}}$ Visiting Lecturer, Department of Economic Sciences, National and Kapodistrian University of Athens, \\ Athens, Greece \\ ${ }^{c}$ Associate Professor, Faculty of Nursing, National and Kapodistrian University of Athens, Greece
}

${ }^{*}$ ) Corresponding author:

George Katharakis, Mathematician, Ph.D Candidate,

Faculty of Nursing,

National and Kapodistrian University of Athens, Greece,

Address: 23 Papadiamantopoulou, Athens

Tel/Fax: +30 2107461598

Email: gkathar@nurs.uoa.gr

\begin{abstract}
Frontier techniques have been used to measure healthcare provider efficiency in hundreds of published studies. Although these methods have the potential to be useful to decision makers, their utility is limited by both methodological questions concerning their application. The aim of this paper is to examine the data envelopment analysis (DEA) and stochastic frontier analysis (SFA) results in order to facilitate a common understanding about the adequacy of these methods, defining any differences in healthcare efficiency estimation. A two-stage bootstrap DEA method and the Translog formula of the SFA were performed. Multi-inputs and multi-outputs were used in both of the approaches assuming two scenarios either including environmental variables or not. The introduced environmental variables were regressed with the bias corrected estimations derived from the first step of the two-stage bootstrap DEA model. In the Translog SFA functional form, these variables were introduced as shifted. Thirty-two Greek public hospital units constitute the sample. The main output of the analysis was that the efficiency scores increased with the incorporation of environmental variables in the SFA model, with the average efficiency score to become from 0.85 to 0.89 . However, DEA and SFA were found to yield divergent efficiency estimates due to many factors such as the nature of the environmental variables, the measurement error and other random factors. Environmental variables being hospital status and geographical position were found significantly correlating with inefficiency, while patient mobility was not found strongly correlating. The analysis concludes that there is a need for careful attention by stakeholders since the nature of the data and its availability influence the measurement of the efficiency and thus it is necessary to be specific when choosing the appropriate mathematical form in order to test the behavior which generates the data.
\end{abstract}

Keywords: Efficiency, Data Envelopment Analysis (DEA), Stochastic Frontier Analysis (SFA), bootstrap, Translog form, OR in Health Services 


\section{Introduction}

Governments all over the world face the difficult task of managing the complexities of controling healthcare costs while at the same time ensuring that patients receive not only a high quality of care, but also that this care is delivered as efficiently as possible [1]. As a result, payers and purchasers have begun to use frontier efficiency measurement techniques in order to measure the performance of the healthcare sector with the aim of supporting their decisions on healthcare units' performance. More commonly used techniques are data envelopment analysis (DEA) and stochastic frontier analysis (SFA) which employ quite distinct methodologies for frontier estimation and efficiency measurement, each with associated strengths and weaknesses. Specifically, "...non-statistical approaches such as DEA have the disadvantage of assuming no statistical noise, but have the advantage of being non-parametric and requiring few assumptions about the underlying technology. SFA models on the other hand have the attraction of allowing for statistical noise, but have the disadvantage of requiring strong assumptions as to the form of the frontier" [2]. DEA is favored where measurement error is unlikely to pose much of a threat and where the assumptions of neoclassical production theory are in question. Conversely, SFA should have the advantage in coping with severe measurement error and where simple functional forms provide a close match to the properties of the underlying production technology. Gong and Sickles [3] report findings along similar lines so that "...as mis-specification of functional form becomes more serious, DEA's appeal (vis-à-vis SFA) becomes more compelling" [3].

Hospital units evaluations have to date been carried out using mostly DEA-based methodologies. During the last twenty years, non-parametric and parametric methods have been increasingly employed to measure and analyze the productive performance of healthcare services. The healthcare sector is a unique area of application, and one in which the measurement of efficiency has burgeoned over the past few years. Mortimer $[4,5]$ highlighted the need for parallel application of competing methods for frontier estimation and efficiency measurement. Thus, the set of pair-wise comparisons is steadily growing as new methods for frontier estimation and efficiency measurement arise to address the shortcomings of more traditional methods.

Thereby, in the efficiency analysis literature there has been considerable interest in reconciling SFA and DEA [6]. Two studies that compared SFA and DEA are Chirikos and Sear [7] for US hospitals and Jacobs [2] for hospitals in the UK where both studies found divergent estimations between the results from the two approaches. Linna [8] examined cost efficiency of Finish hospitals and found that SFA and DEA generated similar results. The last 5 years Desaia [9], Smith [10], Assaf [11], Lee [12] share the same prospect that neither DEA nor SFA can be regarded as clearly dominant, and that other mixed extended methods like quantile regression, or corrected ordinary least squares (COLS) can be used and likely can yield more reliable estimates, representing useful alternative approaches in efficiency studies. Likewise, more recent studies, Kontodimopoulos [13], Martin [14], Veen [15], Nedela [16], suggest that SFA and DEA approaches along with other techniques are viable alternatives for analyzing the impact of environmental variables and dynamic effects on hospital cost efficiency, generating similar but more consistent results in empirical application to the efficiency analysis of healthcare units. Moreover, the majority of the researchers agree on the need of being aware of using both DEA and SFA methods, along with determining the sources of productivity factors by regressing the efficiency scores against a set of environmental variables.

Under this context, an empirical application of both two-stage bootstrap DEA approach of Simar and Wilson [17] and SFA with the Translog functional form (SFA translog) on a sample of Greek public hospital units has been conducted in order to analyze cost efficiency estimations comparatively. Based on the fact that SFA is mostly used in literature under one input and many outputs or the opposite [2,11], in this paper, multi-inputs and multi-outputs 
are used in both of the approaches assuming two scenarios, either including environmental variables or not. Thus, the analysis is focused on discussing the results derived by the models' applications. Therefore, the main purpose of our study is to examine the "behavior"

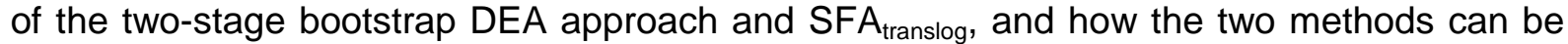
used to make valid inferences about the effects of environmental variables on estimated cost efficiency. Nevertheless, the present study aims to simply highlight the importance of the information (without sensationalizing it) from the policymakers perspective and in so doing perhaps provide additional information resource on which they can base their decisions and policies. Hospital managers and policymakers can become more effective decision makers by understanding the relationships between efficiency and these environmental variables.

The rest of the paper is organized as follows: Section 2 provides a short bibliographical review on efficiency evaluation under DEA and SFA models. Section 3 provides a thorough description regarding the research framework along with the data analysis approach. Section 4 provides an outline of the results and main findings obtained from the used techniques; section 5 provides a discussion on the implications of the research and concludes with some suggestions for future work.

\section{Literature survey}

Many researchers have applied methods in order to evaluate hospital efficiency, such as Data Envelopment Analysis (DEA) and Stochastic Frontier Analysis (SFA). These frontier methods use an efficient frontier to identify the efficiency of hospital units relative to a reference set of healthcare units. DEA is a non-parametric approach that uses mathematical programming to identify the efficient frontier. SFA is a parametric approach that hypothesizes a functional form and uses the data to econometrically estimate the parameters of that function using the entire set of DMU's. However, the two methods differ in some key theoretical aspects. DEA measures efficiency relative to a nonparametric estimate of an unobserved true frontier, conditional on observed data [17]. On the other hand, SFA requires the specification of a functional form for the frontier, and assumptions about the distributions of the random error and inefficiency error terms, which might be very restrictive [18].

Table 1 outlines the most recent published papers that have been used in at least one pairwise comparison of the DEA/SFA methods. A small sample of the 21 papers used is shown in the table which has been derived from the systematic literature review of Katharakis \& Katostaras [19]. The analysis revealed that both approaches of DEA and SFA were found to yield divergent efficiency estimates due to many factors such as statistical noise and inputs and outputs definition, as well as data availability. Nevertheless, different modeling approaches have advantages and disadvantages and the choice of the most appropriate estimation method should depend on the type of organizations under investigation, the perspective taken and the quality of the available data as Hollingsworth [20, 21] also highlights. The issue of testing whether an environmental variable has a significant influence on the production process and any resulting efficiency estimates has been also reviewed. Jacobs, Smith and Street [22] note that the literature provides several different recommendations on how to handle such variables. The Katharakis \& Katostaras [19] review, points out that researchers, besides the combination of models to measure efficiency, introduce environmental variables in the analysis, aiming at better understanding the relationship of these factors to efficiency and thus at better decision making. 
Table 1. Systematic literature review on combined DEA and SFA applications

\begin{tabular}{|c|c|c|c|c|}
\hline \multirow{2}{*}{ Author(s) } & \multirow{2}{*}{ Sample/Period } & \multicolumn{2}{|c|}{ Efficiency Techniques } & \multirow{2}{*}{$\begin{array}{l}\text { SFA model Input / } \\
\text { Output combination }\end{array}$} \\
\hline & & DEA model & SFA model & \\
\hline $\begin{array}{l}\text { Bryce et al } \\
\quad(2000)\end{array}$ & $\begin{array}{l}585 \text { HMOs operating } \\
\text { from } 1985 \text { through } 1994\end{array}$ & $\begin{array}{l}\text { VRS input } \\
\text { oriented }\end{array}$ & $\begin{array}{l}\text { SPF (stochastic } \\
\text { production frontier) }\end{array}$ & 4 inputs / 1 output \\
\hline $\begin{array}{l}\text { Chirikos and } \\
\text { Sear (2000) }\end{array}$ & $\begin{array}{c}232 \text { acute care hospitals } \\
\text { of Florida over the period } \\
1982-1993\end{array}$ & $\begin{array}{l}\text { VRS input } \\
\text { oriented }\end{array}$ & $\begin{array}{l}\text { SFR(stochastic } \\
\text { frontier regression) }\end{array}$ & 1 input / 6 outputs \\
\hline $\begin{array}{l}\text { Giuffrida } \\
\text { and } \\
\text { Gravelle } \\
(2001)\end{array}$ & $\begin{array}{l}90 \text { FHSAs (Family Health } \\
\text { Service Authority) }\end{array}$ & $\begin{array}{l}\text { CRS \& VRS input } \\
\text { oriented }\end{array}$ & $\begin{array}{l}\text { COLS (corrected } \\
\text { ordinary least } \\
\text { squares) \& stochastic } \\
\text { frontier with half } \\
\text { normal, exponential } \\
\text { and truncated errors } \\
\text { (SFN, SFE, SFT) \& } \\
\text { canonical regression } \\
\text { (CAN). }\end{array}$ & 1 input / 16 outputs \\
\hline $\begin{array}{l}\text { Jacobs } \\
(2001)\end{array}$ & $\begin{array}{l}232 \text { UK NHS Trusts } \\
\text { Hospitals during the } \\
\text { years } 1995 / 6\end{array}$ & $\begin{array}{l}\text { VRS input } \\
\text { oriented }\end{array}$ & $\begin{array}{l}\text { SCF (stochastic cost } \\
\text { frontier) }\end{array}$ & 1 input / 17 outputs \\
\hline $\begin{array}{l}\text { Giokas } \\
(2001)\end{array}$ & 91 hospitals in 1992 & $\begin{array}{l}\text { CRS \& VRS input } \\
\text { oriented }\end{array}$ & SFA (OLS estimation) & 1 input / 4 outputs \\
\hline $\begin{array}{l}\text { Ondrich and } \\
\text { Ruggiero } \\
\text { (2001) }\end{array}$ & $\begin{array}{l}\text { simulation study of } 200 \& \\
1000 \text { units }\end{array}$ & $\begin{array}{l}\text { VRS input } \\
\text { oriented }\end{array}$ & $\begin{array}{l}\text { stochastic vs. } \\
\text { deterministic } \\
\text { production frontier } \\
\text { Cobb-Douglas }\end{array}$ & 1 input / 5 outputs \\
\hline $\begin{array}{l}\text { Desai et al } \\
\quad(2005)\end{array}$ & 10 units & $\begin{array}{l}\text { CRS \& VRS input } \\
\text { oriented }\end{array}$ & $\begin{array}{l}\text { chance-constrained } \\
\text { formulation of DEA } \\
\text { (stochastic model) }\end{array}$ & 2 inputs / 1 output \\
\hline $\begin{array}{l}\text { Assaf } \\
(2008)\end{array}$ & $\begin{array}{c}101 \text { health care } \\
\text { foodservice operations in } \\
\text { Australia \& USA }\end{array}$ & $\begin{array}{l}\text { CRS \& VRS input } \\
\text { oriented }\end{array}$ & SFA & 1 input / 7 outputs \\
\hline $\begin{array}{l}\text { Lee et al } \\
(2009)\end{array}$ & $\begin{array}{l}107 \text { nursing homes from } \\
\text { Kansas and Missouri. }\end{array}$ & $\begin{array}{l}\text { VRS input } \\
\text { oriented }\end{array}$ & $\begin{array}{l}\text { SFA (COLS) } \\
\text { corrected ordinary } \\
\text { least squares }\end{array}$ & 16 inputs / 1 output \\
\hline $\begin{array}{l}\text { Kontodimop } \\
\text { oulos et al } \\
(2010)\end{array}$ & 124 dialysis facilities & $\begin{array}{l}\text { VRS input } \\
\text { oriented }\end{array}$ & $\begin{array}{l}\text { SFA (typical Cobb- } \\
\text { Douglas model) }\end{array}$ & 2 inputs / 1 outputs \\
\hline $\begin{array}{l}\text { Martin } \\
(2010)\end{array}$ & $\begin{array}{l}30 \text { primary care trusts } \\
\text { (PCTs) during the period } \\
2004-06\end{array}$ & $\begin{array}{l}\text { CRS \& VRS input } \\
\text { oriented }\end{array}$ & $\begin{array}{l}\text { SFA (COLS) } \\
\text { corrected ordinary } \\
\text { least squares }\end{array}$ & 7 inputs / 1 output \\
\hline
\end{tabular}

Source: Adjusted from Katharakis \& Katostaras (2012)

Moreover, it should be noted that there is an existence of a number of ways to account for inputs in frontier efficiency estimations. These possibilities are however dependent on the method employed. DEA can accommodate multiple inputs, while SFA requires an aggregated single variable for input oriented efficiency calculations. Using multiple inputs in natural unit, technical efficiency is measured which proves highly appropriate where information on input prices is not available. Aggregation of the input variables required by the SFA is usually represented by total costs. In other words, cost efficiency is measured. Ideally, health output should be measured as an increment to patient health status. However, since this is technically impossible to measure, in all hospital efficiency studies intermediate outputs of various kinds are used instead.

The most commonly used SFA method is the Cobb-Douglas functional form and Quadratic formula or Translog formula, using one input or one output most of the time, along with existing environmental factors which are analyzed separately. DEA has the advantage that it is able to manage complex production environments with multiple inputs and outputs, but as a non-statistical method it does not produce the usual diagnostic tools with which to judge 
the goodness-of-fit of the model specifications. While SFA can discriminate between efficient units, DEA has a limited ability to do this, although both techniques can discriminate between inefficient hospitals [2]. Considering the above and the purpose of the study, the choice of multi-inputs and multi-outputs was adopted for the SFA Translog formula, indicating the innovation suggested by this paper.

\section{Materials and Methods}

\subsection{Sample synthesis and variables definition}

Following Katharaki [1] research work, both DEA and SFA model was applied on the sample of 32 Obstetrical and Gynecological (O\&G) units located in five of the ten geographical Greek NHS regions. The evaluation is focused on DEA and SFA methods that allow initial comparisons to be made and some early conclusions to be reached. Based mainly on the data fit to the model, the following are used in this study as inputs:

- $\quad$ number of beds;

- $\quad$ number of medical personnel;

- total expenditure for the provision of care.

Regarding the selected inputs, hospital size and capacity were measured by the number of beds. Most studies exclude the number of physicians because independent contractors exist who may admit patients. For the purpose of the current study, it is important to include them as an input since wide discrepancies exist between the numbers of specialized physicians in different regions of the country which largely determine the volume of the O-G services that a hospital can perform [1]. The input "total expenditure", refers to the grand total expenditure and not to the individual resource component costs (doctors' salaries, nurses' salaries, etc.). The introduction of "operating expenses" into the set of inputs aims at an estimate of the degree of utilization of the financial resources in relation to the "services" produced.

It should be mentioned that quantitative expression of factors determining services provided by healthcare units display significant difficulties referring to both the factors' identification and their functional relationship to the health product. According to this the "health product" of healthcare units is expressed through:

- $\quad$ the number of female patients treated;

- $\quad$ the number of examinations in outpatient clinics;

- the number of lab tests.

The use of the number of O\&G lab tests and patient days as outputs of the study was selected in order to become criteria for efficiency assessment of units as proxy factors of the degree of resource utilization. These criteria have been utilized in a plethora of related studies [23, 24].

In this analysis, the environmental variables in order to analyze the efficiency are the same for both the stochastic frontier model and the second stage truncated regression of DEA model. For the specification of environmental variables, we followed Rosko and Mutter [25, 26] along with Nedelea and Fannin [16]. The primary variable of interest is Geographical Position (GP) dummy (one if the hospital is an urban and zero if it a rural one) which is used to test whether rural O\&Gs are more or less cost efficient than non-rural hospitals. Two more dummy variables that define the reputation of the hospital, indicated by:

- Hospital Status (HS) (one with high status, referring to tertiary and university hospitals and zero with lower status, referring to secondary and non-university hospitals) and

- $\quad$ Patient Mobility (PM) to seek healthcare services in well-known hospitals (one referring to hospitals that accept patients from other geographical regions and zero otherwise) 
are included to control the internal pressure associated with efficiency estimation. The HS variable was introduced to our analysis based on the fact that it explains the organizations' structure. Following Assaf [11], Kontodimopoulos [13] and Chen et al [27] the status of the hospital depends on the position of the hospital (university hospital or not), the experience of the doctors and the technological infrastructure of the hospital. Moreover, the PM is a variable which gives the patients' mobility to well-known tertiary hospitals for their better treatment. PM variable has also been used by Ippoliti and Falavigna [28] who argue that patient mobility may be due to a previous personal experience or to remarks by someone closer to the patient and that the perception mechanism is linked to reputation. In this study the classification of each hospital of the sample regarding PM was based on Katharaki [1] who describes the mobility of patients through regions in order to seek healthcare services. Variable definitions are presented in Table 2.

Table 2. Summary statistics and variable definitions

\begin{tabular}{|c|c|c|c|c|}
\hline \multirow{2}{*}{$\begin{array}{l}\text { DEA \& SFA } \\
\text { variables }\end{array}$} & \multirow{2}{*}{ Variable definition } & \multicolumn{3}{|c|}{32 Obstetrical and Gynecological units (O\&G) } \\
\hline & & Total sample & Mean & SD \\
\hline \multicolumn{5}{|l|}{ Inputs } \\
\hline $\mathrm{KL}$ & Beds & 1,082 & 34 & 49.62 \\
\hline PR & Medical personnel & 412 & 13 & 21.25 \\
\hline SD & $\begin{array}{l}\text { Total expenditures } \\
(€)\end{array}$ & $49,353,333$ & $1,542,292$ & $1,739,309.57$ \\
\hline \multicolumn{5}{|l|}{ Outputs } \\
\hline NOS & Patients hospitalized & 50,209 & 1,569 & $2,655.86$ \\
\hline $\mathrm{EIA}$ & $\begin{array}{l}\text { Patients examined in } \\
\text { outpatient clinics }\end{array}$ & 215,088 & 6,722 & $8,596.12$ \\
\hline ERG & Lab tests & $1,900,462$ & 59,389 & $63,251.35$ \\
\hline \multicolumn{5}{|l|}{$\begin{array}{l}\text { Environmental } \\
\text { Variables }\end{array}$} \\
\hline GP & $\begin{array}{l}\text { Geographical } \\
\text { position }(0,1)\end{array}$ & - & 0.315422 & 0.236803 \\
\hline HS & Hospital status $(0,1)$ & - & 0.298822 & 0.237677 \\
\hline MP & Patient mobility $(0,1)$ & - & 0.265422 & 0.232318 \\
\hline
\end{tabular}

\subsection{Data analysis}

The empirical research was conducted using two scenarios: the application of DEA and SFA model either with environmental variables or without them. The programming language $R$ environment version 2.15 was used for the data analysis, along with the software package FEAR 1.15 of Wilson [29] and the software package FRONTIER 4.1 of Coelli [30] in order to carry out the DEA and SFA estimations.

The SFA Translog and the DEA CRS approaches were used to conduct the empirical analysis of the first scenario which was not investigated the environmental effect on inefficiency. With regard to the method used, DEA, a method originating from Farrell's [31] seminal work, popularized by Charnes et al. [32] and Banker et al. [33], provides a nonparametric alternative to parametric frontier production function analysis. This non-parametric method allows the calculation of technical efficiency measured that can be either input or output oriented [32, 34, 35, 36, 1]. To estimate the efficiency of the Greek public units used in the sample, the CCR (Charnes, Cooper and Rhodes) input oriented model was used [32]. With the help of input and output variables, the cost-minimizing input vector for each hospital 
is calculated using linear programming [16]. Next, cost efficiency is measured as the ratio of minimum cost to observed cost and takes a value between 0 and 1 , where a value of 1 indicates a cost efficient hospital [37]. With input-oriented DEA, the linear programming model is configured so as to determine how much the input use of a firm could contract if used efficiently in order to achieve the same output level. The cost efficiency measures the factor by which the observed cost can be reduced if the hospital selects the optimal input and operates at a technically efficient point [16].

Regarding SFA, this parametric method was based on the quantitative economy theory. According to Farrell [31] theory of efficiency measurement, Aigner, Lovell, and Schmidt [38] and Meeusen and van den Broeck [39] independently constructed an error structure of stochastic frontier analysis to measure productive efficiency of firm. SFA is a parametric approach, and is suited to measure efficiencies of stochastic industry for input/output information. To complete the model estimation, it is important to specify and use the suitable functional form. Translog and Cobb-Douglas cost functions are the most well known formulas for research, especially in evaluating the efficiency of units. Translog function is very commonly used. It is a generalization of the Cobb-Douglas function and it's a flexible functional form providing a second order approximation. Cobb-Douglas and Translog functions are linear in parameters and can be estimated using least squares methods. For the purpose of our empirical research the Translog function has been used since we had multi-inputs and multi-outputs of the O\&G units. In this paper, we use the Translog form (formula embedded in the package frontier 4.1 for multi-inputs and outputs) with three inputs and three outputs provided in the following equation (equation 1), respectively:

$$
\begin{aligned}
& \ln \left(y_{i t}\right)=\beta_{0}+\beta_{1} \ln \left(K L_{i t}\right)+\beta_{2} \ln \left(S D_{i t}\right)+\beta_{3} \ln \left(P R_{i t}\right)+\frac{1}{2} \beta_{4} \ln \left(K L_{i t}^{2}\right)+\frac{1}{2} \beta_{5} \ln \left(S D_{i t}^{2}\right)+ \\
& +\frac{1}{2} \beta_{6} \ln \left(P R_{i t}^{2}\right)+\beta_{7} \ln \left(K L_{i t}\right) * \ln \left(S D_{i t}\right)+\beta_{8} \ln \left(K L_{i t}\right) * \ln \left(P R_{i t}\right)+\beta_{9} \ln \left(S D_{i t}\right) \ln \left(P R_{i t}\right)+V_{i t}-U_{i t}
\end{aligned}
$$

\section{(Equation 1)}

where

$y_{i t}=$ the variables of the outputs (NOS= Patients hospitalized, EIA=Patients examined in outpatient clinics, ERG=Lab tests) for the $\mathrm{i}^{\text {th }}$ healthcare unit at time $\mathrm{t}$

$K L_{i t}=$ Beds for the $\mathrm{i}^{\text {th }}$ healthcare unit at time $\mathrm{t}$

$S D_{i t}=$ Total expenditures $(€)$ for the $\mathrm{i}^{\text {th }}$ healthcare unit at time $\mathrm{t}$

$P R_{i t}=$ Medical personnel for the $\mathrm{i}^{\text {th }}$ healthcare unit at time $\mathrm{t}$

$V_{i t}=$ Random error

$U_{i t}=$ Non-negative random variable (or technical inefficiency)

Data analysis of the second scenario was based on the two-stage bootstrap DEA method and the Translog formula of the SFA including the explanatory variables that have been defined (see section 3.1). The differences between the SFA and the DEA approaches are that the SFA requires functional forms on the production frontier, and assumes that firms may deviate from the production frontier not only due to technical inefficiency but also from measurement errors, statistical noise or other non-systematic influences [40]. For this purpose, in the formula of the SFA Translog frontier, the second non-negative random variables $U_{i t}$ which are assumed to be independently and identically distributed normal random variables as truncations at zero with $Z_{i t} \delta$ means and variances $\sigma_{u}^{2}$ $\left(U_{i t} \sim\right.$ iid $\left.N\left(0, \sigma_{u}^{2}\right)\right)$ are known as the technical inefficiency effects and in our model was 
formed under the environmental factors, which were earlier defined. Thus equation 2 represents the inefficiency effects model and is the following for the second scenario:

$$
U_{i t}=\sigma_{0}+\sigma_{1} G P_{i t}+\sigma_{2} H S_{i t}+\sigma_{3} M P_{i t}+W_{i t}
$$

(Equation 2)

where

$G P_{i t}=$ dummy variable of geographical position $(0,1)$ for the $i^{\text {th }}$ healthcare unit at time $t$

$H S_{i t}=$ dummy variable of hospital status $(0,1)$ for the $\mathrm{i}^{\text {th }}$ healthcare unit at time $\mathrm{t}$

$M P_{i t}=$ dummy variable of moving patient $(0,1)$ for the $\mathrm{i}^{\text {th }}$ healthcare unit at time $\mathrm{t}$

$W_{i t}=$ Random error $\left(W_{i t} \sim N\left(0, \sigma_{w}^{2}\right)\right)$

This research focus on how the environmental variables influence hospital cost efficiency. From the first stage of the DEA approach the efficiency scores are estimated, then regressed in the second stage by the three environmental variables in order to investigate if the hospital inefficiency is changed by these explanatory variables. The second stage of the two-stage DEA model is conducted by regressing environmental variables on the healthcare units' CRS technical inefficiency scores which are predicted from the first step of the two-stage DEA model. The units' technical inefficiency scores are used as the dependent variable. The set of environmental variables are used as independent variables for the two-stage DEA model. The estimated inefficiency scores are normally bounded between zero and one. Applying the method of truncated regression with such a dependent variable that its values are bounded between zero and one will lead to biased and inconsistent estimators, since the truncated method is likely to predict inefficiency scores which are greater than one [37]. A disadvantage of DEA is that it has no statistical properties. Simar and Wilson $[17,29]$ have recently addressed this problem and showed that it is possible to obtain statistical properties for DEA via the use of the "bootstrap" approach. The bootstrap approach can also be extended to account for the impact of environmental variables on efficiency. These variables are viewed as possibly affecting the production process but not under the control of managers. Determining how these variables influence efficiency is thus essential for deriving performance improvement strategies. The procedure used in this study follows that of Simar and Wilson [17, 29]. A comprehensive discussion of the bootstrap procedure and its advantages are also provided in Simar and Wilson [17, 29].

Both of these above approaches have been popular the last years among researchers in order to explain valid inferences about the impact of environmental variables on hospital cost efficiency. What is clear from the existing literature is that none of the existing papers (to our knowledge) have adopted the bootstrapped DEA procedure comparing it with an SFA model for multi-inputs and multi-outputs. However, its deep theoretical background and computational difficulties, its inflexibility in handling multiple outputs and the somewhat arbitrary distribution assumptions about the inefficiency term, are among the reasons why this method occupies a relatively small portion of the literature of efficiency studies in healthcare [20, 21, 41]. Thus, the current research is innovative in this context.

\section{Results}

Table 3 shows summary of efficiency scores (per unit and per geographical area) estimated by both DEA CRS, DEA bootstrap and SFA Translog model under the two scenarios of the analysis, with and without determinants. Efficiency intervals in two methods DEA and SFA are respectively between zero and one. Moreover with regard to the first scenario, the DEA CRS mean efficiency score was $81.56 \%$ while the mean efficiency estimated using SFA $\mathrm{Eq}_{1}$ was $85.07 \%$. Note the increased score of approximately $120 \%$ for the SFA $\mathrm{Eq}_{1}$ estimation of units N9, N16, and N29, something that can be explained by the structure of the hospital 
organization since they have a small amount of $O \& G$ beds and of which the two are regional hospitals.

Table 3. The efficiency score of the units of the sample using DEA and SFA model under the two scenarios

\begin{tabular}{|c|c|c|c|c|c|c|c|}
\hline & $\begin{array}{l}\text { Hospitals with O\&G } \\
\text { units by region }\end{array}$ & $\begin{array}{l}\text { DEA CRS } \\
\text { efficiency } \\
\text { score }\end{array}$ & $\begin{array}{c}\text { SFA } \\
\text { efficiency } \\
\text { score (Eq1) }\end{array}$ & $\begin{array}{c}\% \\
\text { change }\end{array}$ & $\begin{array}{c}\text { DEA bootstrap } \\
\text { efficiency } \\
\text { score (bias } \\
\text { corrected) }\end{array}$ & $\begin{array}{c}\text { SFA } \\
\text { efficiency } \\
\text { score } \\
(\text { Eq1+2) }\end{array}$ & $\begin{array}{c}\% \\
\text { change }\end{array}$ \\
\hline & Attica mean score & 0.8007 & 0.8206 & $2.48 \%$ & 0.6582 & 0.8886 & $35.00 \%$ \\
\hline N1 & $\begin{array}{c}\text { A (GH Attica } \\
\text { Alexandra) }\end{array}$ & 0.9512 & 0.76038 & $-20.06 \%$ & 0.7716 & 0.8917 & $15.57 \%$ \\
\hline $\mathrm{N} 2$ & $\begin{array}{c}\text { B (Obstetrical E. } \\
\text { Venizelou) }\end{array}$ & 1.0000 & 0.96840 & $-3.16 \%$ & 0.8096 & 0.9762 & $20.58 \%$ \\
\hline N3 & $\begin{array}{c}\text { C (GH Nea lonia Agia } \\
\text { Olga) }\end{array}$ & 1.0000 & 0.93015 & $-6.99 \%$ & 0.8108 & 0.9621 & $18.66 \%$ \\
\hline N4 & D (GH Athina) & 0.7196 & 0.88657 & $23.20 \%$ & 0.6199 & 0.9452 & $52.48 \%$ \\
\hline N5 & E (GH Laiko) & 0.7794 & 0.72841 & $-6.54 \%$ & 0.6922 & 0.8027 & $15.96 \%$ \\
\hline N6 & $\begin{array}{c}\mathrm{F} \text { (GH Attica } \\
\text { Evvagelismos) }\end{array}$ & 0.5038 & 0.52935 & $5.07 \%$ & 0.4327 & 0.9456 & $118.53 \%$ \\
\hline N7 & G (GH Attica Elpis) & 0.5916 & 0.75046 & $26.85 \%$ & 0.5093 & 0.6842 & $34.34 \%$ \\
\hline N8 & H (GH Agios Savvas) & 1.0000 & 0.90595 & $-9.41 \%$ & 0.8145 & 0.9596 & $17.81 \%$ \\
\hline N9 & I (GH Metaxas) & 0.4162 & 0.91890 & $120.78 \%$ & 0.3701 & 0.8966 & $142.26 \%$ \\
\hline N10 & J (GH Janneio Piraeus) & 0.8463 & 0.66225 & $-21.75 \%$ & 0.7516 & 0.7293 & $-2.97 \%$ \\
\hline \multirow[t]{2}{*}{ N11 } & K (GH Nikaia Piraeus) & 1.0000 & 0.98596 & $-1.40 \%$ & 0.8482 & 0.9810 & $15.66 \%$ \\
\hline & $\begin{array}{c}\text { Remaining } \\
\text { continental Greece } \\
\text { mean score }\end{array}$ & 0.7387 & 0.8421 & $14.00 \%$ & 0.6363 & 0.8961 & $40.83 \%$ \\
\hline N12 & L (GH Agrinio) & 0.8891 & 0.82467 & $-7.25 \%$ & 0.8034 & 0.8810 & $9.66 \%$ \\
\hline N13 & M (GH Patra) & 1.0000 & 0.71870 & $-28.13 \%$ & 0.8078 & 0.8244 & $2.05 \%$ \\
\hline N14 & $\begin{array}{c}\mathrm{N} \text { (GH University of } \\
\text { Patra) }\end{array}$ & 0.4777 & 0.87582 & $83.34 \%$ & 0.4167 & 0.9336 & $124.05 \%$ \\
\hline N15 & $\mathrm{O}$ (GH Amaliada) & 1.0000 & 0.79965 & $-20.04 \%$ & 0.8691 & 0.8669 & $-0.25 \%$ \\
\hline N16 & P (GH Leivadia) & 0.4337 & 0.96563 & $122.65 \%$ & 0.3552 & 0.9322 & $162.44 \%$ \\
\hline N17 & Q (GH Halkida) & 0.6852 & 0.86720 & $26.56 \%$ & 0.5947 & 0.9693 & $62.99 \%$ \\
\hline N18 & R (GH Lamia) & 0.6603 & 0.84691 & $28.26 \%$ & 0.5840 & 0.8745 & $49.74 \%$ \\
\hline \multirow[t]{2}{*}{ N19 } & S (GH Amfissa) & 0.7634 & 0.83798 & $9.77 \%$ & 0.6597 & 0.8867 & $34.41 \%$ \\
\hline & Thessaly mean score & 0.8036 & 0.7479 & $-6.93 \%$ & 0.6852 & 0.8356 & $21.95 \%$ \\
\hline N20 & $\mathrm{T}$ (GH Larisa) & 0.8084 & 0.67411 & $-16.61 \%$ & 0.7135 & 0.7988 & $11.96 \%$ \\
\hline N21 & U (GH Volos) & 1.0000 & 0.83900 & $-16.10 \%$ & 0.8458 & 0.9071 & $7.25 \%$ \\
\hline \multirow[t]{2}{*}{ N22 } & V (GH Trikala) & 0.6024 & 0.73069 & $21.30 \%$ & 0.4965 & 0.8009 & $61.31 \%$ \\
\hline & $\begin{array}{l}\text { Peloponnese mean } \\
\text { score }\end{array}$ & 0.9037 & 0.9354 & $3.51 \%$ & 0.7755 & 0.9388 & $21.06 \%$ \\
\hline N23 & W (GH Argos) & 1.0000 & 0.97582 & $-2.42 \%$ & 0.8572 & 0.9843 & $14.83 \%$ \\
\hline N24 & X (GH Navplio) & 1.0000 & 0.95069 & $-4.93 \%$ & 0.8223 & 0.8961 & $8.97 \%$ \\
\hline N25 & Y (GH Trikala) & 0.9818 & 0.87170 & $-11.21 \%$ & 0.8705 & 0.9164 & $5.27 \%$ \\
\hline N26 & Z (GH Korinthos) & 1.0000 & 0.96252 & $-3.75 \%$ & 0.8669 & 0.9730 & $12.24 \%$ \\
\hline N27 & AA ((GH Sparti) & 0.9096 & 0.97093 & $6.74 \%$ & 0.8232 & 0.9854 & $19.70 \%$ \\
\hline N28 & AB (GH Kalamata) & 1.0000 & 0.92440 & $-7.56 \%$ & 0.8318 & 0.8966 & $7.79 \%$ \\
\hline \multirow[t]{2}{*}{ N29 } & AC (GH-HC Kyparissia) & 0.4348 & 0.89203 & $105.16 \%$ & 0.3572 & 0.9201 & $157.59 \%$ \\
\hline & $\begin{array}{l}\text { Aegean Islands mean } \\
\text { score }\end{array}$ & 0.8311 & 0.9073 & $9.17 \%$ & 0.7175 & 0.9033 & $25.90 \%$ \\
\hline N30 & AD (GH Mytilini) & 0.8590 & 0.87164 & $1.47 \%$ & 0.7764 & 0.8572 & $10.41 \%$ \\
\hline
\end{tabular}




\begin{tabular}{|c|c|c|c|c|c|c|c|}
\hline N31 & AE (GH Rhodos) & 1.0000 & 0.87509 & $-12.49 \%$ & 0.8369 & 0.8857 & $5.83 \%$ \\
\hline N32 & $\begin{array}{c}\text { AF (GH Syros } \\
\text { Varvakios) }\end{array}$ & 0.6343 & 0.97526 & $53.75 \%$ & 0.5392 & 0.9669 & $79.32 \%$ \\
\hline & TOTAL mean score & $\mathbf{0 . 8 1 5 6}$ & $\mathbf{0 . 8 5 0 7}$ & $4.30 \%$ & $\mathbf{0 . 6 9 4 5}$ & $\mathbf{0 . 8 9 2 4}$ & $\mathbf{2} 2.49 \%$ \\
\hline
\end{tabular}

From table 3 it is derived that the efficiency scores obtained from DEA CRS and SFA without determinants differ, which is consistent with Chirikos \& Sear [7]. The Spearman's Rank Correlation between the mean of efficiencies calculated in different methods was then estimated. The results are listed in Table 4; as it is seen there is no significant correlation in the different methods. Even though it is inappropriate to compare efficiency scores across different methods, valuable information can be retrieved from the frequency structure of the different sets of efficiency scores. Comparing the frequency plots of efficiency scores (Figure 1 and 2) one recognizes that DEA CRS scores are on average higher and with more fully efficient observations than those obtained under SFA $A_{E q 1}$. SFA $A_{E q 1}$ has, on the other hand, more observations to the left tail of the efficiency distribution.

Table 4. DEA CRS vs. SFA $A_{E q 1}$ Spearman's Rank Correlations rho

\begin{tabular}{l}
\hline coefficient $=0.241759$ \\
\hline$p$-value $=0.1825>0.05$ \\
\hline
\end{tabular}

Note: coefficient was insignificant at $0.05 \%$ level.

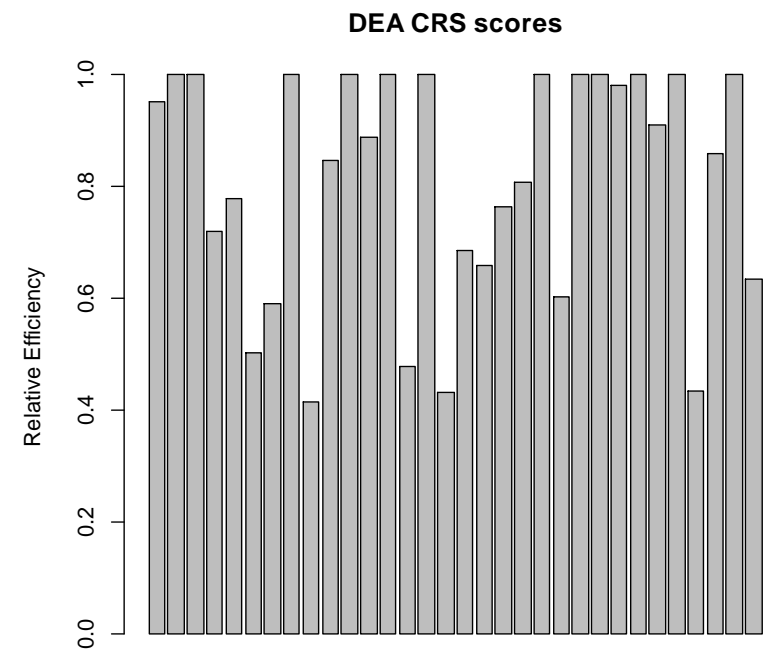

O\&G units

Figure 1. Frequency Plot DEA CRS scores

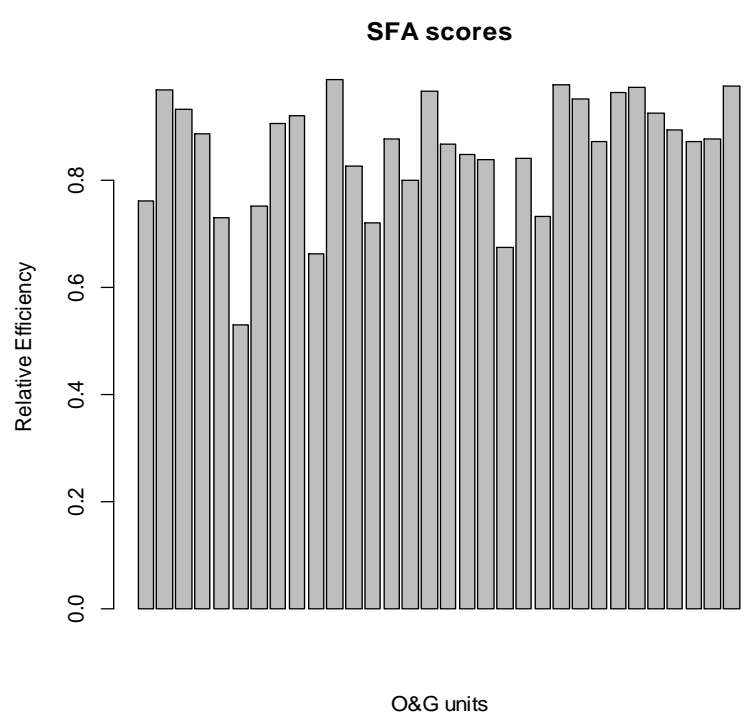

Figure 2. Frequency Plot SFA $\mathrm{Eq} 1_{1}$ scores

Subsequently, results of the Maximum Likelihood Estimation of equation 1 of the SFA Translog model are provided in Table 5. All variables of the stochastic frontier regression proved significant. 
Table 5. SFA Results without determinants

\begin{tabular}{|c|c|c|c|}
\hline & Coefficient & Std. Error & t value \\
\hline (Intercept) & $-4.5136 \mathrm{e}+03$ & $9.8655 \mathrm{e}-01$ & $-4575.1851^{* \star *}$ \\
\hline LogKL & $-3.5771 \mathrm{e}+02$ & $9.5342 \mathrm{e}-01$ & $-375.1913^{* * *}$ \\
\hline LogSD & $3.4379 \mathrm{e}+03$ & $9.0588 \mathrm{e}-01$ & $3795.0585^{* \star *}$ \\
\hline LogPR & $-1.6328 \mathrm{e}+02$ & $9.4125 \mathrm{e}-01$ & $-173.4770^{* * *}$ \\
\hline & & & $12.1463^{* * *}$ \\
\hline$\sigma^{2}$ & $4.5061 \mathrm{e}-02$ & $3.7098 \mathrm{e}-03$ & $21.7157^{* \star *}$ \\
\hline $\boldsymbol{V}$ & $9.9025 \mathrm{e}-01$ & $4.5601 \mathrm{e}-02$ & $\mathbf{2 3 . 2 6 2 9 2}$ \\
\hline
\end{tabular}

Note: $* *$ denotes significance at $1 \%$ level, $* *$ significance at $5 \%$ level, $*$ significance at $10 \%$ level

Provided that DEA models incorporate only discretionary inputs and the fact that environmental factors that may influence efficiency are not taken into consideration in the analysis, scenario 2 was introduced and under the null hypothesis of positive effect of the environmental variables GP, HS and PM on inefficiency, SFA Translog under equation 1 and 2 was performed. In other words, GP, HS and PM dummies were included into the SFA Translog model as shifted variables or else variables that explain the inefficiency level. Table 3 summarizes the estimated efficiency scores that are likely to substantially increase, while Table 6 outlines the significance of the introduced variables of the MSE estimation of $\mathrm{SFA}_{\mathrm{Eq}(1+2)}$. In particular, the two environmental variables GP and HS found to explain inefficiency as significant. This is also derived from Ippoliti and Falavigna [28] and Chen et al [27]. The variable PM was not found to be significantly correlating. The same finding was also reached by Ippoliti and Falavigna [28], who argue that patient mobility and inefficiency are not strongly correlating, indicating that both aspects need to be taken into account and that direct relationships may not necessarily exist.

Moreover, the coefficients of the $\mathrm{KL}$ and $\mathrm{PR}$ variables found to be negatively correlating with inefficiency before and after the explanatory variables introduction (Table 5 \& 6). According to Chen et al [27] hospitals with a large bed size, experience a lower inefficiency score. On the other hand, the variable SD was found to be significantly correlating with inefficiency in both scenarios. This finding is in line with Katharaki [1] results, indicating the need for more rational utilization of economic resources.

In addition, the likelihood ratio test on one-sided error term, i.e. the test of the presence of the inefficiency term, is significant suggesting that the inefficiency term is highly appropriate in the analysis. Parameter $\mathrm{y}$ is also significant but smaller than the one derived from the $S_{S F} A_{E q 1}$ (i.e. without determinants), meaning that the variance of the inefficiency term takes up a much smaller part of the total variance than before. In other words, compared to the previous regression, more of the total variance of the error term is now captured by the variance of the white noise rather than inefficiency since a certain portion of inefficiency was explained by determinants and thus is smaller than before.

Table 6. SFA Results with determinants

\begin{tabular}{|c|c|c|c|}
\hline & Coefficient & Std. Error & t value \\
\hline (Intercept) & $-4.7798 \mathrm{e}+03$ & $9.8891 \mathrm{e}-01$ & $-4833.3560^{\star \star *}$ \\
\hline LogKL & $-3.7874 \mathrm{e}+02$ & $9.6128 \mathrm{e}-01$ & $-393.9903^{\star * \star}$ \\
\hline LogSD & $3.4567 \mathrm{e}+03$ & $9.2055 \mathrm{e}-01$ & $3755.0573^{\star \star \star}$ \\
\hline LogPR & $-1.5535 \mathrm{e}+02$ & $9.4804 \mathrm{e}-01$ & $-163.8625^{\star * \star}$ \\
\hline $\boldsymbol{G P}$ & $-7.9177 \mathrm{e}-01$ & $1.8268 \mathrm{e}-01$ & $-4.3341^{\star \star *}$ \\
\hline $\boldsymbol{H S}$ & $6.9518 \mathrm{e}-01$ & $1.4319 \mathrm{e}-01$ & $4.8551^{\text {} 01}$ \\
\hline $\boldsymbol{M P}$ & $2.2101 \mathrm{e}-01$ & $1.1332 \mathrm{e}-01$ & 1.9504 \\
\hline $\boldsymbol{\sigma}^{2}$ & $1.9973 \mathrm{e}-02$ & $1.0085 \mathrm{e}-02$ & $1.9805^{\star}$ \\
\hline
\end{tabular}




\begin{tabular}{|c|c|c|c|}
\hline $\boldsymbol{Y}$ & $9.6286 \mathrm{e}-01$ & $3.4351 \mathrm{e}-01$ & $2.8030^{\star *}$ \\
\hline \multicolumn{3}{|c|}{ Log Likelihood function } & $\mathbf{3 2 . 8 7 4 4 9}$ \\
\hline
\end{tabular}

Note: ${ }^{* * *}$ denotes significance at $1 \%$ level, ${ }^{* *}$ significance at $5 \%$ level, ${ }^{*}$ significance at $10 \%$ level

Following Simar and Wilson [17], a DEA bootstrap was conducted. The results are presented in Table 3 and Table 8 respectively. The Spearman's Rank Correlation between the mean of efficiencies scores of DEA bootstrap and SFA $\mathrm{Eq1}_{1+2}$ were also calculated. The results are listed in Table 7; as it is seen, there is still no significant correlation in the different methods.

Table 7. Boootsrap DEA CRS vs. SFA $\mathrm{Eq1}_{1+2}$ Spearman's Rank Correlations rho

\begin{tabular}{c}
\hline coefficient $=0.21004$ \\
\hline$p$-value $=0.2475>0.05$ \\
\hline
\end{tabular}

Note: coefficient was insignificant at $0.05 \%$ level.

Considering that the most common approach in testing the impact of environmental variables on efficiency involves the use of two-stage analysis, where according to McDonald [42] "Stage 1 is used to use nonparametric DEA to calculate the efficiency with which output is produced from physical inputs. Stage 2, on the other hand, uses regression to relate efficiency scores to factors seen to influence" (p. 792), and that Simar and Wilson [17] have recently criticized this approach, and suggested instead of a bootstrap approach in which it is possible to improve the accuracy of the regression estimates, we regressed the derived bias corrected bootstrap efficiency scores on the environmental variables GP, HS and PM (following the methodology presented in section 3.2). Note that 2000 bootstrap replications $(B=2000)$ was used, following Simar and Wilson [44] who highlighted the adequate coverage of the confidence intervals by choosing the appropriate number of replications. Table 9 provides the original DEA efficiency scores, the DEA bootstrapped efficiency scores, the BIAS (computed as the difference between original DEA and bootstrapped DEA) of the original DEA, the standard error of the bootstrap values, and the lower and upper bounds of the DEA-bootstrap confidence intervals. It is evident from the data in the first column of Table 9 that there are twelve efficient healthcare units on the frontier of best practices with a technical efficiency score equal to one. However, when considering the bootstrapping results (column 2 of Table 9) none of the O\&G units appear to be close to the frontier. Since the bias is large relatively to the variance in every case, the bootstrap estimates are preferred to the original estimates [43]. The original efficiency estimates lie also outside the estimated confidence intervals in the last two columns of Table 9 in every instance. This is due to the bias in the original estimates, and the fact that the confidence interval estimates are correct for the bias. These results therefore reinforce the fact that the DEA bootstrap model is more superior to the traditional DEA model in estimating the efficiency scores.

Table 8. Average Bootstrapped Efficiency Results

\begin{tabular}{|c|c|c|c|c|c|c|}
\hline $\begin{array}{l}\text { Hospitals with O\&G } \\
\text { units by region }\end{array}$ & $\begin{array}{c}\text { DEA CRS } \\
\text { efficiency } \\
\text { score }\end{array}$ & $\begin{array}{c}\text { DEA } \\
\text { bootstrap } \\
\text { efficiency } \\
\text { score } \\
\text { (bias } \\
\text { corrected) }\end{array}$ & Bias & Std. error & LB & UB \\
\hline Attica & & & & & & \\
\hline
\end{tabular}




\begin{tabular}{|c|c|c|c|c|c|c|}
\hline N1 & 0.9512 & 0.7716 & 0.1796 & 0.0315 & 0.6033619 & 0.9388931 \\
\hline $\mathrm{N} 2$ & 1.0000 & 0.8096 & 0.1904 & 0.0291 & 0.6335647 & 0.9904158 \\
\hline N3 & 1.0000 & 0.8108 & 0.1892 & 0.0280 & 0.6414505 & 0.9895848 \\
\hline N4 & 0.7196 & 0.6199 & 0.0997 & 0.0196 & 0.5064849 & 0.7127992 \\
\hline N5 & 0.7794 & 0.6922 & 0.0872 & 0.0096 & 0.6000972 & 0.7709694 \\
\hline N6 & 0.5038 & 0.4327 & 0.0711 & 0.0316 & 0.3770568 & 0.4987433 \\
\hline N7 & 0.5916 & 0.5093 & 0.0823 & 0.0235 & 0.4417462 & 0.5861719 \\
\hline N8 & 1.0000 & 0.8145 & 0.1855 & 0.0289 & 0.6318485 & 0.9896944 \\
\hline N9 & 0.4162 & 0.3701 & 0.0461 & 0.0254 & 0.3262460 & 0.4120655 \\
\hline N10 & 0.8463 & 0.7516 & 0.0947 & 0.0060 & 0.6700102 & 0.8384421 \\
\hline N11 & 1.0000 & 0.8482 & 0.1518 & 0.0102 & 0.7265148 & 0.9891503 \\
\hline \multicolumn{7}{|c|}{$\begin{array}{c}\text { Remaining } \\
\text { continental Greece }\end{array}$} \\
\hline N12 & 0.8891 & 0.8034 & 0.0857 & 0.0029 & 0.7420322 & 0.8827905 \\
\hline N13 & 1.0000 & 0.8078 & 0.1922 & 0.0295 & 0.6345639 & 0.9913400 \\
\hline N14 & 0.4777 & 0.4167 & 0.0610 & 0.0275 & 0.3662360 & 0.4732295 \\
\hline N15 & 1.0000 & 0.8691 & 0.1309 & 0.0061 & 0.7661170 & 0.9905848 \\
\hline N16 & 0.4337 & 0.3552 & 0.0785 & 0.1180 & 0.2832661 & 0.4301016 \\
\hline N17 & 0.6852 & 0.5947 & 0.0905 & 0.0122 & 0.5339088 & 0.6774223 \\
\hline N18 & 0.6603 & 0.5840 & 0.0763 & 0.0089 & 0.5282276 & 0.6537839 \\
\hline N19 & 0.7634 & 0.6597 & 0.1037 & 0.0114 & 0.5894786 & 0.7555504 \\
\hline \multicolumn{7}{|c|}{ Thessaly } \\
\hline N20 & 0.8084 & 0.7135 & 0.0949 & 0.0094 & 0.6253504 & 0.8011794 \\
\hline N21 & 1.0000 & 0.8458 & 0.1542 & 0.0110 & 0.7198583 & 0.9908029 \\
\hline N22 & 0.6024 & 0.4965 & 0.1059 & 0.0495 & 0.4171662 & 0.5966570 \\
\hline \multicolumn{7}{|c|}{ Peloponnese } \\
\hline N23 & 1.0000 & 0.8572 & 0.1428 & 0.0072 & 0.7619327 & 0.9912032 \\
\hline N24 & 1.0000 & 0.8223 & 0.1777 & 0.0185 & 0.6861725 & 0.9894525 \\
\hline N25 & 0.9818 & 0.8705 & 0.1113 & 0.0040 & 0.7828186 & 0.9714313 \\
\hline N26 & 1.0000 & 0.8669 & 0.1331 & 0.0062 & 0.7680271 & 0.9895243 \\
\hline N27 & 0.9096 & 0.8232 & 0.0864 & 0.0031 & 0.7534963 & 0.9027766 \\
\hline N28 & 1.0000 & 0.8318 & 0.1682 & 0.0135 & 0.7203223 & 0.9900779 \\
\hline N29 & 0.4348 & 0.3572 & 0.0776 & 0.1042 & 0.2915040 & 0.4312552 \\
\hline \multicolumn{7}{|c|}{ Aegean Islands } \\
\hline N30 & 0.8590 & 0.7764 & 0.0826 & 0.0047 & 0.6953294 & 0.8499056 \\
\hline N31 & 1.0000 & 0.8369 & 0.1631 & 0.0123 & 0.7155387 & 0.9906999 \\
\hline N32 & 0.6343 & 0.5392 & 0.0951 & 0.0244 & 0.4727831 & 0.6288665 \\
\hline
\end{tabular}

At the last step of our analysis, the effect of determinants on inefficiency was estimated through the model of the truncated regression. Results of the Maximum Likelihood Estimation for the parameters on DEA CRS initial scores and on the bias corrected bootstrap scores are provided in Table 9. Comparing the results with those from the SFA method (Table 5 and 6 ) all variables proved significant and likely similar. The estimated coefficients and standard errors for the models are also presented in Table 9.

Table 9. Estimated effects of environmental variables in both approaches 


\begin{tabular}{|c|c|c|c|}
\hline \multicolumn{4}{|c|}{ DEA results without the effect of determinants } \\
\hline & Coefficient & Std. Error & t value \\
\hline (Intercept) & 0.6604 & 0.05347 & $12.352^{* * *}$ \\
\hline $\mathrm{KL}$ & -0.0001643 & 0.002434 & -0.007 \\
\hline SD & $2.467 \mathrm{e}-07$ & $8.526 \mathrm{e}-08$ & $2.893^{\star \star}$ \\
\hline PR & -0.01773 & 0.006159 & $-2.880^{\star *}$ \\
\hline \multicolumn{3}{|c|}{ Log Likelihood function } & 13.694348 \\
\hline \multicolumn{4}{|c|}{ Two- stage DEA results with determinants after bootstrap } \\
\hline & Coefficient & Std. Error & t value \\
\hline (Intercept) & 0.5664788 & .0458635 & $12.35^{\star \star *}$ \\
\hline $\mathrm{KL}$ & -0.000144 & .0018592 & -0.08 \\
\hline SD & $2.23 e-07$ & $6.72 e-08$ & $3.31^{\star \star}$ \\
\hline PR & -0.0170342 & .0052943 & $-3.22^{\star \star}$ \\
\hline GP & -0.3272004 & .1759237 & $-3.86^{* * *}$ \\
\hline HS & 0.2450065 & .1442114 & $3.70^{\star \star \star}$ \\
\hline MP & 0.1418569 & .1156827 & 1.23 \\
\hline \multicolumn{3}{|c|}{ Log Likelihood function } & 18.57163 \\
\hline
\end{tabular}

Note: ${ }^{* *}$ denotes significance at $1 \%$ level, $* *$ significance at $5 \%$ level, $*$ significance at $10 \%$ level

Furthermore, Table 9 outlines the positive and highly significant coefficient of GP, and negative and highly significant coefficient of HS dummy, suggesting that the geographical position of a healthcare unit, as well as the hospital status of the unit influence their performance. According to Prochazkova [45] if a hospital is situated in a bigger municipality in terms of its population, it seems to be more efficient. This could be explained by the fact that population may influence inefficiency of hospitals due to various channels; the occupancy rate may be higher in bigger cities and thus hospitals demonstrate more patient days.

\section{Discussion}

This paper has proposed a framework to measure the efficiency of hospital units, aiming to examine the adequacy of two different methods that are commonly used in literature. Both DEA and SFA approaches are efficiency frontier analysis, and provide a suitable way of approaching the measurement of hospital efficiency. Hospitals are aimed to minimize inputs and operating efficiently. Under this context, this paper applies the two methods to evaluate the efficiency of 32 hospital units. In particular, a two-stage bootstrap DEA method and the Translog formula of the SFA were performed. Multi-inputs and multi-outputs were used in both of the approaches assuming two scenarios either including environmental variables or not.

The main output of the analysis was that the efficiency scores increased with the incorporation of environmental variables in the SFA model and decreased when bootstrap is applied. Specifically, the analysis shows that the average efficiency scores of SFA $\mathrm{Eq}_{1}$ model is the highest (0.85), followed by DEA $A_{C C R}$ model $(0.81)$, while the SFA $A_{E q(1+2)}$ model increased (0.89) when environmental variables were taken into consideration. This result is in line with Prochazkova [45], and Nedelea [16]. Low efficiency scores are indicated wrongly as inefficient, while instead are being caused by various non-discretionary variables that are beyond the control of hospitals. In addition, when applying the bootstap approach and regressing the bias corrected estimations on the same environmental variables, the average score decreases to 0.69 . Considering the bootstrapped results, none of the healthcare units appear to be close to full efficiency and even the rankings are not preserved. This confirms previous results from Simar and Wilson $[43,44]$ who argued that traditional DEA models tend sometimes to present firms as efficient, when they are actually not. This bias depends on 
sample size $\mathrm{n}$ as well as on "the curvature of the frontier and the magnitude of the density at the frontier" [46, 47].Consistent to Codrero et al [48] who outlines that one stage approach overestimates efficiency especially in the small sample due to the loss of discrimination power in DEA after including additional variables (non-discretionary inputs), the above finding could be further justified from the small sample of our analysis.

Moreover, the significant correlation of environmental variables GP and HS with the inefficiency are in line with the findings of Ippoliti and Falavigna [28] and Chen et al [27], indicating that future research would include a more detailed study of organizational factors $[49,50]$. In addition, the present study provides valuable information regarding deployment of medical staff and beds and the utilization of financial resources. SFA results indicate the need for measures taken regarding the more rational utilization of economic resources. Briefly, all of the above are believed to constitute useful information for the managers of the hospital units, which will assist them in making decisions that will lead to the more effective operation of the units.

With regard to the methodology used, a large number of efficiency analysis studies use SFA with cross-sectional data. However, the cross-sectional stochastic frontier model has been shown to have some limitations. Schmidt and Sickles [51] noted three limitations of SFA with cross section data. First, in cross-sectional stochastic frontier models, firm-specific efficiency is unidentified and researchers typically estimate expectations of efficiency conditional on a composite residual. Second, cross-sectional stochastic frontier models require specific distributional assumptions for each error component in order to estimate efficiency. Third, the efficiency error term is assumed to be independent of regressors (i.e., inputs and outputs), an assumption which is very restrictive.

Alternatively, one can use the two-stage approach along the line of Simar and Wilson [17] with cross-sectional data. Using DEA to estimate efficiency scores in the first stage, one can avoid potential misspecification problems that affect SFA. In the semi-parametric model defined by Simar and Wilson [17], the assumptions of a linear functional form and truncated normal errors in the second stage appear to be less restrictive as compared with a fully parametric approach. Further, the assumption of independent errors in SFA is avoided in the model defined by Simar and Wilson [17] where the first stage estimation does not require independence between the efficiency scores and the inputs and outputs. From the results, it is clearly that the DEA and SFA approach have many advantages and disadvantages as well. Both techniques constitute two alternatives solutions for analyzing the effects of the environmental variables on hospital efficiency. It is shown that similar and consistent results have been obtained in our empirical application from the two methods considering the efficiency analysis of O\&G units. Moreover, researchers should be aware of using the bootstrap algorithm proposed by Simar and Wilson [17]. It should also be checked the impact of the environmental variables on estimated efficiency, wherever this is feasible.

\section{Conclusion and managerial implications}

Different methods have been utilized for adjusting efficiency scores to control the environmental factors [35, 37]. The purpose of our work was to reach a wide variety of stakeholders, each of which faces different pressures and values in the selection and application of efficiency measures. Moreover, this paper is intended to create a common understanding among these stakeholders about the adequacy of tools to measure healthcare efficiency. Given the limitations of frontier techniques, it may be that they are best employed in tandem, when possible, and if different methods suggest similar directions for results then the validity of such findings is enhanced. Since the healthcare industry is one area where efficiency measurement may have a direct policy impact, a cautious approach is necessary. 
As well as refining methods, the means of making efficiency results useful in a practical setting needs careful attention. Although steps are being taken in this direction there is still some way to go. The use of models with restrictions placed upon the weight given to variables, in order to reflect underlying production models or policy values, is also an interesting area requiring further research to justify the use of such restrictions. There is still room for the use of more advanced methods in order to measure the efficiency of the health and healthcare sectors. The quality of data available for use may also be a problem to be addressed. Notwithstanding the caveats mentioned earlier regarding making comparisons across studies, and that perhaps work needs to be undertaken to think of ways of making efficiency studies comparable, these findings may have important policy implications for the organizational structure of healthcare delivery.

Besides that, the paper has a number of other limitations. The panel has been restricted to one year of observations in an unbalanced form with a small sample of the healthcare units. According to Coelli $[35,37]$ SFA models should be applied in much bigger samples. Thus, an extension to a balanced panel with more observations for each hospital would enable a more extensive inters temporal comparison of the results. Furthermore, focusing solely on the improvement of the overall inefficiency, a policy maker or a manager may opt to alter a specific decision variable. Therefore, relying only on the overall DEA score for efficiency analysis provides incomplete information to guide decisions, while it is known that the nature of the data and its availability influence the measurement of the efficiency. It is thus necessary to carefully address issues regarding improving the managerial decision-making process through quantitative analysis.

To sum up, careful attention should be paid to the purpose of the analysis and to how results are to be used. In particular, if they are to be used to influence economic behavior - for example in the form of setting targets, or identifying candidates for inspection - then the potential costs of making incorrect inferences should be recognized. The results of this analysis should not serve as a background for immediate policy responses. It rather points out special circumstances and provides motivation for further research. At the same time, it is fully acknowledged that economic analysis of Greek hospitals is not telling the whole story. It should be supplemented by surveys of satisfaction with the quality of care or surveys of patient criteria for choosing the hospital unit, and thus include quality of care, other managerial factors and even clinical research and political change, as exogenous variable factors, in order for the analysis to provide an overall picture.

\section{Acknowledgements}

The current paper constitutes part of the thesis titled "Evaluating Efficiency of Health Care Units with Stochastic Frontier Analysis". This research has been co-financed by the European Union (European Social Fund - ESF) and Greek national funds through the Operational Program "Education and Lifelong Learning" of the National Strategic Reference Framework (NSRF) - Research Funding Program: "Heracleitus II. Investing in knowledge society through the European Social Fund". Moreover, I would like to thank Ms. Theodora Kapsalis for her useful help in editing the paper.

\section{References}

[1]. M. Katharaki, Approaching the management of hospital units with an operation research technique. The Case of thirty two Greek Obstetric and Gynaecology Public Units, Health Policy 85. (1) (2008) 19-31. 
[2]. R. Jacobs, Alternative methods to examine hospital efficiency: Data Envelopment Analysis and Stochastic Frontier Analysis, Health Care Management Science. 4 (2001) 103-115.

[3]. B. Gong, R. Sickles, Finite sample evidence on the performance of stochastic frontiers and data envelopment analysis using panel data, Journal of Econometrics. 51 (1992) 259-284.

[4]. D. Mortimer, A Systematic Review of Direct DEA vs SFA/DFA Comparisons, Centre for Health and Evaluation, Australia, 2002, Working Paper 136.

[5]. D. Mortimer, Methods for the Measurement of Hospital Efficiency: A Comparison of Frontier Estimation Techniques in a Sample of Victorian Public Hospitals, Department of Economics, Monash University: Unpublished Master of Economics (Honours) thesis, 2001.

[6]. L. Mutter, D. Rosko, H. Greene, W. Wilson, Translating frontiers into practice: taking the next steps toward improving hospital efficiency, Medical Care Research and Review. 68(1) (2011) 35-195.

[7]. T. Chirikos, A. Sear, Measuring hospital efficiency: a comparison of two approaches, Health Services Research. 34 (6) (2000)1389-1408.

[8]. M. Linna, Measuring hospital cost efficiency with panel data models, Health Economics. 7 (1998) 415-427.

[9]. A. Desaia, S. Ratick, A. Schinnar, Data envelopment analysis with stochastic variations in data, Socio-Economic Planning Sciences. 39 (2005)147-164.

[10]. P. Smith, A. Street, Measuring the efficiency of public services: the limits of analysis, Journal of the Royal Statistical Society: Series A (Statistics in Society). 168 (2) (2005) 401-417.

[11]. A. Assaf, K. Matawie, Cost efficiency modeling in healthcare food service operations, International Journal of Hospitality Management. 27(4) (2008) 604-613.

[12]. R. Lee, M. Bott, B. Gajewski, R. Taunton, Modelling Efficiency at the Process Level: An Examination of the Care Planning Process in Nursing Homes. Health Services Research. 44 (1) (2009)15-32.

[13]. N. Kontodimopoulos, N. Papathanasiou, A. Flokou, Y. Tountas, D. Niakas, The Impact of Non-Discretionary Factors on DEA and SFA Technical Efficiency Differences, Journal of Medical Systems. 35 (5) (2010) 981-989.

[14]. S. Martin, P. Smith, A comparison of English primary care trusts. Preliminary statistical analysis, The Health Foundation Inspiring Improvement 2010.

[15]. S. Veen, Comparative Efficiency Analysis from the Perspective of the Dutch Health Care Insurer. Determining the Usefulness of Efficiency Measures for Contracting Primary Care Organizations, Health Economics at the Erasmus University Rotterdam (Master Thesis), 2012.

[16]. C. Nedelea, J. Fannin, Efficiency Analysis of Rural Hospitals: Parametric and Semiparametric Approaches. No 119725, Annual Meeting, Birmingham, Alabama from Southern Agricultural Economics Association 2012.

[17]. L. Simar, P. Wilson, Estimation and inference in two-stage, semi-parametric models of production processes, Journal of Econometrics. 136 (2007) 31-64.

[18]. J. Newhouse, Frontier estimation: how useful a tool for health economics? Journal of Health Economics. 13 (1994) 317-322. 
[19]. G. Katharakis, T. Katostaras, SFA vs. DEA for measuring healthcare efficiency: A systematic review, (2012),( under review)

[20]. B. Hollingsworth, Efficiency and productivity change in the English National Health service: Can data envelopment analysis provide a robust and useful measure? Journal of Health Services Research and Policy. 8 (2003).

[21]. B. Hollingsworth, The measurement of efficiency and productivity of health care delivery. Health Economics. 17 (10) (2008)1107-1128.

[22]. R. Jacobs, P. Smith, A. Street, Measuring Efficiency in Health Care: Analytic Techniques and Health Policy, Cambridge, Cambridge University Press, 2006.

[23]. JA. Chilingerian, HD. Sherman, Benchmarking physician practice patterns with DEA: a multi-stage approach for cost containment, Annals of Operations Research. 67(1) (1996) 83-116.

[24]. JA. Chilingerian, HD. Sherman, Health care applications. From Hospitals to Physicians, from productive efficiency to quality frontiers. In: Cooper WW, Seiford LM, Zhu J, editors. Handbook on data envelopment analysis. Boston/London: Kluwern Academic Publisher, 2004.

[25]. D. Rosko, L. Mutter, Inefficiency differences between Critical Access Hospitals and prospectively paid rural hospitals, Journal of Health Politics, Policy and Law. 35(1) (2010) 95-126.

[26]. D. Rosko, L. Mutter, What have we learned from the application of stochastic frontier analysis to U.S. hospitals? Medical Care Research and Review. 68(1) (2011) 75S$100 \mathrm{~S}$.

[27]. A. Chen, Y. Hwang, B. Shao, Measurement and sources of overall and input inefficiencies: Evidences and implications in hospital services, European Journal of Operational Research. 161 (2005) 447-468.

[28]. R. Ippoliti, G. Falavigna, Efficiency of the medical care industry: Evidence from the Italian regional system, European Journal of Operational Research. 217 (2012) 643652.

[29]. P. Wilson, FEAR: A software package for frontier efficiency analysis with R, SocioEconomic Planning Sciences, doi:10.1016/j.seps.2007.02.001.

[30]. T. Coelli, A guide to FRONTIER version 4.1: A computer program for stochastic frontier production and cost function estimation. CEPA Working Paper 96/07, Department of Econometrics, University of New England, Armidale, Australia.

[31]. M. Farrell, The measurement of productive efficiency, Journal of the Royal Statistical Society Series A. 120 (1957) 253-281.

[32]. A. Charnes, W. Cooper, E. Rhodes, Measuring the efficiency of decision-making units, European Journal of Operational Research. 2 (1978) 429-44.

[33]. R. Banker, A. Charnes, W. Cooper, Some Models for Estimating Technical and Scale Inefficiencies in Data Envelopment Analysis, Management Science. 30 (1984) 10781092.

[34]. A. Charnes, W. Cooper, Preface to topics in Data Envelopment Analysis, Annals of Operations Research. 2 (1985) 59-94.

[35]. T. Coelli, R. Prasada, D. Rao, G. Battese, An introduction to efficiency and productivity analysis (Boston, Kluwer Academic). Communication from the Commission to the Council and to the European Parliament. (COM/2006/0481 final) Efficiency and equity in European education and training systems \{SEC(2006) 1096\}. 
[36]. W. Cooper, M. Seiford, J. Zhu, Handbook on Data Envelopment Analysis, Boston (Kluwer Academic Publisher) 2004.

[37]. T. Coelli, D. Rao, C. O'Donnell, G. Battese, An introduction to efficiency and productivity analysis (2nd ed.), New York, 2005, Springer.

[38]. D. Aigner, C, Lovell, P. Schmidt, Formulation and estimation of stochastic frontier production functions, Journal of Econometrics. 6 (1997) 21-37.

[39]. W. Meeusen, J. van den Broeck, Efficiency estimation from Cobb-Douglas production function with composed error, International Economic Review, (1977), 18, 435-444.

[40]. A. Admassie, F. Matambalya, Technical Efficiency in Small and Medium Scale Enterprises: Evidences from a Survey of Enterprises in Tanzania - Easter Africa, Eastern Africa Social Science Research Review. 17 (2) (2002) 1-29.

[41]. A. Worthington, Frontier Efficiency Measurement in Healthcare: A Review of Empirical Techniques and Selected Applications, Medical Care Research and Review. 61(2) (2004) 1-36.

[42]. J. McDonald, Using least squares and tobit in second stage DEA analyses, European Journal of Operational Research.197 (2009) 792-8.

[43]. L. Simar, P. Wilson, Sensitivity analysis of efficiency scores: How to bootstrap in nonparametric frontier models, Management Science. 44 (1998) 49-61.

[44]. L. Simar, P. Wilson, Estimating and bootstrapping Malmquist indices, European Journal of Operational Research. 115 (1999) 459-471.

[45]. J. Prochazkova, Efficiency of Hospitals in the Czech Republic: DEA \& SFA Applications, Charles University in Prague, Faculty of Social Sciences, Institute of Economic Studies (2011) thesis.

[46]. L. Simar, P. Wilson, A general methodology for bootstrapping in non-parametric frontier models, Journal of Applied Statistics. 27 (2000a) 779-802.

[47]. L. Simar, P. Wilson, Statistical inference in nonparametric frontier models: The state of the art, Journal of Productivity Analysis. 13 (2000b) 49-78.

[48]. J. Cordero, F. Pedraja, D. Santin, Alternative approaches to include exogenous variables in DEA measures: A comparison using Monte Carlo, Computers and Operations Research. 36 (2009) 2699-2706.

[49]. E. Minvielle, B. Dervaux, A. Retbi, Ph. Aegerter, A. Boumendil, M. Guincestre, A. Tenaillon, B. Guidet, Culture, Organizations, and Management in Intensive Care: Construction and Validation of Multidimensional Questionnaire, Journal of Critical Care. 20 (2) (2005) 126-38.

[50]. E. Minvielle, A. Phillipe, B. Dervaux, Assessing Organizational Performance in Intensive Care Units: A French Experience, Journal of Critical Care. 23 (2008) 236-44.

[51]. Schmidt P, Sickles C. Production frontiers and panel data. Journal of Business and Economic Studies. 2 (1984) 299-326.

[52]. M. Oliveira, C. Maisonneuve, S.Bjornerud, Projecting OECD health and long term care expenditures: What are the main drivers? OECD Working Paper No. 477, Paris.

[53]. CK. Cassel, TE. Brennan, Managing medical resources: return to the commons? Journal of the American Medical Association. 297(22) (2007) 2518-21.

[54]. A. Milstein, TH. Lee, Comparing physicians on efficiency, The new England Journal of Medicine. 357(26) (2007) 2649-52. 
[55]. P. Hussey, H. Vries, J. Romley, M. Wang, S.Chen, P. Shekelle, E. McGlynn, A Systematic Review of Health Care Efficiency Measures. Health Services Research. 44(3) (2009) 784-805.

[56]. A. Giuffrida, H. Gravelle, Measuring performance in primary care: Econometric analysis and DEA. Applied Economics. 33 (2) (2001) 163-175.

[57]. R. Rosenman, T. Li, Cost Inefficiency in Washington Hospitals: A Stochastic Frontier Approach Using Panel Data, Health Care Management Science. 4 (2001) 73-81

[58]. C. Bryce, J. Engberg, D. Wholey, Comparing the Agreement among Alternative Models in Evaluating Hmo Efficiency, Health Service Journal. 35(2) (2000) 509-528.

[59]. R. Lee, M. Bott, B. Gajewski, R. Taunton, Modelling Efficiency at the Process Level: An Examination of the Care Planning Process in Nursing Homes, Health Services Research. 44 (1) (2009) 15-32

[60]. K. Alshare, M. Whiteside, Stability analysis for DEA models: an empirical example, Academy of Information and Management Sciences Journal. 8 (2) (2005) 1-16.

[61]. E. Ballestero, J. Segura, Objective measurement of efficiency: applying single price model to rank hospital activities, Computers and Operations Research. 31 (2004) 515532.

[62]. D. Ferrier, V. Valdmanis, Rural hospital performance and its correlates, Journal of Productivity Analysis. 7 (1996) 63-80.

[63]. O. Fried, A. Lovell, S.Schmidt, S. Yaisawarng, Accounting for environmental effects and statistical noise in data envelopment analysis, Journal of Productivity Analysis. 17(1-2) (2002) 157-174.

[64]. D. Giokas, The use of goal programming, regression analysis and data envelopment analysis for estimating efficient marginal costs of hospital services, Journal of MultiCriteria Decision Analysis. 11 (4-5) (2003) 261 - 268.

[65]. M. Katharaki, A Data Envelopment Analysis model for measuring the efficiency impact of telemedicine on Greek obstetric and gynaecology services: Effects on individual hospital unit management, The Journal on Information Technology in Healthcare. 4 (6) (2006) 373-383.

[66]. L. McKay, E. Deily, H. Dorner, Ownership and changes in hospital inefficiency, 19861991. Inquiry (2003) 39 388-399.

[67]. E. McNamara, Welfare effects of rural hospital closures: a nested logit analysis of the demand for rural hospital services, American Journal of Agricultural Economics. 81 (3) (1999) 686-91.

[68]. A. Milstein, TH. Lee, Comparing physicians on efficiency, The new England Journal of Medicine. 357(26) (2007) 2649-52.

[69]. P. Nayar, A. Ozcan, Data envelopment analysis comparison of hospital efficiency and quality, J Med Syst. 32 (3) (2008) 193-199.

[70]. OECD. The Evaluation of Scientific Research: Selected Experiences (Paris: OECD 1997).

[71]. OECD Education at a Glance. OECD Indicators 2005 (OECD Publishing).

[72]. J. Ondrich, J. Ruggiero,.Efficiency measurement in the stochastic frontier model, European Journal of Operational Research. 129 (2001) 434-442

[73]. H. Ozgen, A. Ozcan, Longitudinal analysis of efficiency in multiple output dialysis markets, Health Care Management Science. 7 (2004) 253-261. 
[74]. D. Rosko, Cost efficiency of U.S. hospitals: a stochastic frontier approach, Health Economics. 10 (2001) 539-551.

[75]. D. Rosko, J. Proenca, Impact of network and system use on hospital X-efficiency, Health Care Management Review. 30 (2005) 69-79.

[76]. T. Sexton, M. Leiken, S. Sleeper, The impact of prospective reimbursement on nursing home efficiency. Medical Care. 27 (1989) 154-163.

[77]. E. Thanassoulis, Introduction to the theory and application of data envelopment analysis, A foundation text with integrated software (USA: Kluwer Academic Publishers 2001).

[78]. A. Worthington, An Empirical survey of frontier efficiency measurement techniques in education, Education Economics. 9 (3) (2001) 245-268. 